SYMPOSIUM No. 43

\title{
SOLAR MAGNETIC FIELDS
}

Edited by ROBERT HOWARD
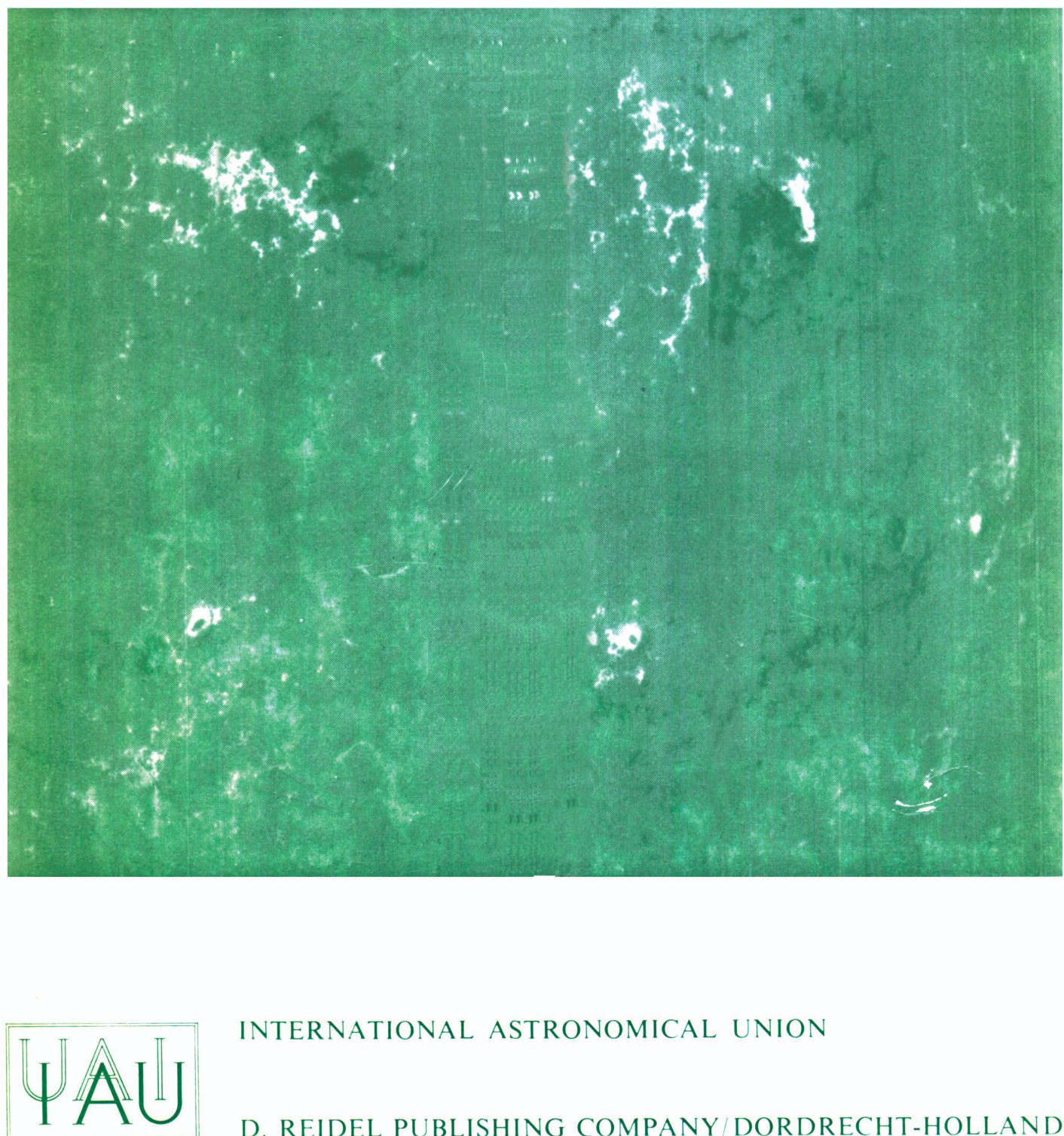

INTERNATIONAL ASTRONOMICAL UNION

D. REIDEL PUBLISHING COMPANY/DORDRECHT-HOLLAND 
SYMPOSIUM No. 43

This volume contains the proceedings of IAU Symposium No. 43 and presents the state of our knowledge of the morphology and the physics of magnetic fields in the solar atmosphere. Among the topics discussed are: problems and interpretation concerning measurement; structure and evolution of small-scale magnetic fields; the relation to transient phenomena in solar active regions; large-scale manifestations of solar activity; and the relationship of the large-scale magnetic fields to the 11-year activity cycle.

The discussion extends from subsurface layers through the photosphere, chromosphere, and the corona to interplanetary space; both radio and optical measurements of magnetic fields are presented and analyzed.

Participants in the symposium represent universities and solar observatories throughout the world. 
SOLAR MAGNETIC FIELDS 
INTERNATIONAL ASTRONOMICAL UNION

UNION ASTRONOMIQUE INTERNATIONALE

SYMPOSIUM No. 43

HELD AT THE COLLEGE DE FRANCE, PARIS, FRANCE

AUGUST 31 TO SEPTEMBER 4, 1970

\title{
SOLAR MAGNETIC FIELDS
}

\author{
EDITED BY \\ ROBERT HOWARD
}

Hale Observatories, Carnegie Institution of Washington, California Institute of Technology, Pasadena, Calif., U.S.A.

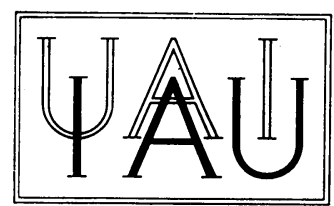

D. REIDEL PUBLISHING COMPANY

DORDRECHT-HOLLAND

1971 
Published on behalf of

the International Astronomical Union

by

D. Reidel Publishing Company, Dordrecht, Holland

All Rights Reserved

Copyright (c) 1971 by the International Astronomical Union

Library of Congress Catalog Card Number 78-159656

ISBN 9027702012

No part of this book may be reproduced in any form, by print, photoprint, microfilm, or any other means, without written permission from the publisher

Printed in The Netherlands by D. Reidel, Dordrecht 


\section{TABLE OF CONTENTS}

PREFACE AND INTRODUCTION

LIST OF PARTICIPANTS

XIII

\section{PART I / INSTRUMENTATION - MEASUREMENT OF} MAGNETIC FIELDS IN THE SOLAR ATMOSPHERE

1. J. M. BECKERS / The Measurement of Solar Magnetic Fields

2. J. V. RAMSAY, R. G. GiOVANELli, and H. R. Gillett / The Culgoora Magnetograph

3. F. Q. ORR ALL / A Complete Stokes Vector Polarimeter 30

4. M. SEMEL / Measurements of Magnetic Fields

5. T. J. JANSSENS and N. K. BAKER / Digital Videomagnetograms in Real Time

6. W. Livingston and J. HAR VeY / The Kitt Peak Magnetograph. IV: 40-Channel Probe and the Detection of Weak Photospheric Fields

7. T. D. FAY and A. A. WYLlER / A Pressure Scanning Fabry-Pérot Magnetometer

62

65

8. R. B. DUNN / Sacramento Peak Magnetograph

9. V. A. котоv / Systematic Errors of the Crimean Vector Magnetograph (presented by A. Severny)

10. R. C. SMITHSON and R. B. LEIGHTON / Analog Video Magnetograms in Real Time

11. G. E. BRUECKNER / A New Completely Digitized Filter Magnetograph

12. E. WIEHR / Difficulties in the Simultaneous Measurement of all Stokes Parameters

13. N. A. ESEPKINA, V. Y. PETRUNKIN, N. S. SOBOLEVA, G. M. TIMOFEEVA, and A. V. REINER / Reduction of the Parasitical Signal of Circular Polarization on an Antenna of Variable Profile with the Help of a Grating

14. A. CACCIANI, M. CIMINo, and M. FOFI / A Short Report on the Magnetic Beam Absorption Filter Research at the Rome Astronomical Observatory

PART II / THE INTERPRETATION OF MAGNETOGRAPH RESULTS - THE FORMATION OF ABSORPTION LINES IN A MAGNETIC FIELD

15. J. O. STENFLO / The Interpretation of Magnetograph Results:

The Formation of Absorption Lines in a Magnetic Field 
16. L. L. HOUSE / Coherence Properties of Polarized Radiation in Weak Magnetic Fields

17. P. MALTBY / Paschen-Back Effect of the Lithium Resonance Doublet in Sunspots

18. V. M. GRIGORYEV and J. M. KATZ / The Crossover and Magneto-Optical Effects in Sunspot Spectra

19. F. K. LA M / The Effect of Collisions on Spectral Line Formation in Solar Magnetic Regions

20. R. GÖHRING / Line Formation in Inhomogeneous Magnetic Fields (presented by W. Mattig)

\section{PART III / OBSERVATIONS OF SUNSPOT AND ACTIVE REGION MAGNETIC FIELDS}

21. E. H. SCHRÖTER / On Magnetic Fields in Sunspots and Active Regions

22. J. RAYROLE / Magnetic Field and Turbulence in Sunspots

23. F.-L. DEUBNER and R. GÖHRING / Photoelectric Measurements of Sunspot Magnetic Fields

24. E. TANDBERG-HANSSEN / Observations of Magnetic Fields in Quiescent Prominences

25. V. BUMB A and J. SUDA / Some Remarks on the Statics and Dynamics of Magnetic Field Structure Development in Active Regions

26. v. A. Kotov / On the Structure of Magnetic Field and Electric Currents of a Unipolar Sunspot (presented by A. Severny)

27. C. ZWAAN and J. BUURMAN / Magnetic Field Strengths Derived from Various Lines in the Umbral Spectrum

28. T. T. TS A P / The Magnetic Fields at Different Levels in the Active Regions of the Solar Atmosphere (presented by $N$. V. Steshenko)

29. H. I. A BDUSSA MATOV / Observations of the Two-Level Structure of Sunspot Magnetic Fields (presented by N. S. Soboleva)

30. E. WIEHR / On the Circular Polarization in Active Regions

31. H. ZIRIN / Application of the Chromospheric Magnetograph to Active Regions (presented by P. Foukal)

32. D. L. SCHATZ / Evolution of the Magnetic Field Configuration in an Active Region

33. F. RODdIER / Line Profiles in Sunspot Umbrae and Penumbrae by Atomic Beam Spectroscopy

34. V. M. GRIGORYEV and G. V. KUKLIN / On the Fine Structure of the Magnetic Field in the Undisturbed Photosphere

35. E. N. FRAZIER / Supergranulation at the Center of the Disk

36. C. J. DURRANT / Magnetographic and Spectrographic Observations of Weakly Active Regions

37. S. I. GOPASYUK and T. T. TSAP / The Magnetic and Velocity Fields and 
Brightness in the Solar Atmosphere (presented by N.V. Steshenko)

38. J. HARVEY and D. HALL / Magnetic Fields Measured with the $10830 \AA$ HeI Line

39. S. MUSMAN / Observations and Interpretation of Supergranule Velocity and Magnetic Fields

40. R. G. GIOVANELLI and J. V. RAMSAY / Vertical Velocities Associated with Plage Region Magnetic Fields

41. A. M. TITLE and J. P. ANDELIN, JR. / Spectra-Spectroheliograph Observations

42. N. R. SHEELEY, JR. / The Time Dependence of Magnetic, Velocity, and Intensity Fields in the Solar Atmosphere

44. S. F. SMITH / H $\alpha$ Structures and Small-Scale Magnetic Field Configurations

45. D. VRA BEC / Magnetic Field Spectroheliograms from The San Fernando Observatory

46. A. SEVER NY / On the Time Fluctuations of Magnetic Fields

47. A. S. TANENBAUM, J. M. WILCOX, and R. HOWARD / Five-Minute Oscillations in the Solar Magnetic Field

48. N. V. Steshen Ko / The Fine Structure of Magnetic Fields and Velocities in Sunspots. (No text nor summary was communicated by the author.)

49. Y. D. ŽHUG ŽDA / The Oscillatory Convection in Penumbrae. (No text nor summary was communicated by the author.)

\section{PART IV / OBSERVATIONS OF MAGNETIC FIELDS ASSOCIATED WITH FLARES AND OTHER TRANSITORY PHENOMENA}

50. R. MICHARD / Solar Magnetic Fields in Association with Flares

51. G. DAIGNE / On Coronal Instability and Moving Radio Features Associated with a Flare Spray

52. E. B. MAYFIELD / Magnetic Fields Associated with Solar Flares

53. T. TAKAKURA / Sunspot Magnetic Fields and High Energy Electrons in Flares

54. A. S. KRIEGER, G. S. VAIANA, and L. P. VAN SPEYBROECK / The X-Ray Corona and the Photospheric Magnetic Field

55. S. ÉNOMÉ and H. TANAKA / Magnetic Fields in the Lower Corona Associated with the Expanding Limb Burst on March 30th 1969 Inferred from the Microwave High-Resolution Observations

56. A. B. SeVer Ny / Electric Currents Connected with the Proton Flares of 7 July and 2 September, 1966

57. K. L. HARVEY, W. C. LIVINGSTON, J. W. HARVEY and C. D. SLAUghter / Observations of Magnetic Field Changes in Active Regions

58. N. ERUSHEV, A. B. SEVERNY, and T. TSAP / The Magnetic Fields and the 
Polarization of Radio Emission in the Active Center of October 1968

59. V. V. KASINSKY / The Position Regularities of Flares Related to the Field

Maximum in Sunspot Groups (presented by G. V. Kuklin)

60. M. J. MARTRES, I. SORU-ESCAUT, and J. RAYROLE / An Attempt to

Associate Observed Photospheric Motions with the Magnetic Field

Structure and Flare Occurrence in an Active Region

61. L. K ǨIVSKÝ / Volume Characteristics of Magnetic-Channel Flares

62. D. A. KUZNETSOV and A. A. ShPitAlnAYA / The Relation Between Dashes and Flares (Physical Nature of the Dash Phenomena) (presented by N. S. Soboleva)

\section{PART V / THEORIES OF SMALL SCALE MAGNETIC FIELDS}

63. P. A. SWEET / Theories of Small-Scale Magnetic Fields

64. P. R. WILSON / Sunspot Magnetic Fields and Umbral Dots

65. E. I. MOGILEVSKY / Statistical Model of Small Scale Discrete Structure of Magnetoplasma in Active Regions of the Sun

66. S. NAGARAJAN / Evolution of Turbulent Magnetic Fields - Approach to a Steady State

67. J. JAKIMIEC / Distribution of the Magnetic Force in the Surface Layers of Sunspots

68. W. H. BOSTICK, V. NARDI, L. GRUNBERGER, and W. PRIOR /

Observation of Solar Flare Type Processes in the Laboratory

69. G. W. PNEUMAN and R. A. KOPP / Interaction of Coronal Material with Magnetic Fields

70. M. KOPECKÝ and G. V. KUKLIN / The Possibility of Magnetic Field Origin in Fine Structure Elements of Solar Features

71. M. KOPECKÝ and V. KOPECKÝ / Anisotropy of Electric Conductivity and

Dissipation of Magnetic Fields

\section{PART VI/OPTICAL AND RADIO OBSERVATIONS OF LARGE SCALE MAGNETIC FIELDS ON THE SUN}

72. G. NEWKIRK, JR. / Large Scale Solar Magnetic Fields and Their Consequences

73. D. M. RUST and J.-R. ROY / Coronal Magnetic Fields Above Active Regions

74. P. CHARVIN / Experimental Study of the Orientation of Magnetic Fields in the Corona

75. M. D. ALTSCHULER, G. NEWKIRK, JR., D. E. TROTTER, and R. HOWARD /

Time Evolution of the Large-Scale Solar Magnetic Field

76. K. H. SCHATten / The Magnetic Field Structure in the Active Solar Corona 
77. G. DAIGNe, M. F. LANTOS-JARRY, and M. PICK / Optical and Radio Observations of Large Scale Magnetic Fields on the Sun

78. S. F. SMERD and G. A. DULK / $80 \mathrm{MHz}$ Radioheliograph Evidence on Moving Type IV Bursts and Coronal Magnetic Fields

79. M. R. KUNDU / Active Regions at Millimeter Wavelengths and the Measurement of Magnetic Fields

80. H. ROSENBERG / Radio-Astronomical Evidence for MagnetoHydrodynamical Pulsations in the Corona

81. U. ANZER and E. TANDBERG-HANSSEN / On the Orientation of Magnetic Fields in Quiescent Prominences

82. G. W. SIMON and R. W. NOYES / Observations of the Coronal Network

83. V. E. STEPANOV and N. F. TJAGUN / Preliminary Results of Spectroscopic Determination of the Coronal Rotation

\section{PART VII/THE POLAR FIELDS OF THE SUN AND THE MAGNETIC ACTIVITY CYCLE}

84. A. B. SEVER Ny / The Polar Fields and Time Fluctuations of the General Magnetic Field of the Sun

85. P. AMBROŽ, V. BUMBA, R. HOWARD, and J. SÝKORA / Opposite Polarities in the Development of Some Regularities in the Distribution of Large-Scale Magnetic Fields

86. G. Y. SMOLKOV / Magnetic Fields in Polar Prominences (presented by

G. V. Kuklin)

87. J. O. Stenflo / Observations of the Polar Magnetic Fields 714

88. Y. NAKAGAWA / A Numerical Study of the Solar Cycle 725

89. G. V. KUKLIN / Dynamics of Large-Scale Magnetic Fields 737

90. J. M. WILCOX / Sector Structure of the Solar Magnetic Field 744

91. J. TUOMINEN / The Sun as a Magnetic Rotator 754

\section{PART VIII / THEORIES OF LARGE SCALE FIELDS AND THE ACTIVITY CYCLE}

92. N. O. WEISS / Theories of Large Scale Fields and the Magnetic Active Cycle

93. F. KRAUSE and K.-H. RÄDLER / Dynamo Theory of the Sun's General Magnetic Field on the Basis of a Mean-Field Magnetohydrodynamics

94. I. K. CSADA / A Dynamo Model for the Large Scale Fields 